\title{
An Algorithm of Emergent Power Control among Wind Farms
}

\author{
Bing Zhang ${ }^{1}$, Zhengjun Xing ${ }^{2}$, Lei Fu ${ }^{1}$, Liang Wang ${ }^{1}$, Yulei Zhang ${ }^{3}$, Zheng Zhou ${ }^{4}$ \\ ${ }^{1}$ Shandong Electric Power Dispatching and Control Center, Shandong Province, Jinan 250000, China \\ ${ }^{2}$ State Grid Chuzhou Power Supply Company, Anhui Province, Chuzhou 239000, China \\ ${ }^{3}$ State Grid Shouguang Power Supply Company, Shandong Province, Shouguang 262700, China \\ ${ }^{4}$ North China Electric Power University, Beijing 102206, China
}

\begin{abstract}
When emergent active power abscission command is given to wind farm cluster by dispatching center, it is necessary for wind farms to coordinate with each other to optimize power abscission distribution. This paper firstly analyzes active power abscission ways of wind farm, and four kinds of power allocation algorithm models, such as wind power allocation algorithm based on combination of cut wind farms, are proposed based on this. Then, a comprehensive evaluation index is constructed by weighted combination of five indicators, such as distribution deviation and the number of cut wind farms, to evaluate the algorithms. Finally, an actual wind power cluster is employed as an example to verify the validity of proposed algorithms. Distribution results and comprehensive evaluation index values indicate that application scope of different allocation algorithm is different and the algorithm based on the cumulative power abscission of wind farms has smallest comprehensive evaluation index value and widest application scope.
\end{abstract}

Key words- wind farms; emergent power abscission; wind power distribution; cumulative amount of emergent power abscission; comprehensive evaluation index

\section{INTRODUCTION}

As the proportion of wind power rapidly increases, abscission of wind farms must be considered in case of an emergency ${ }^{[1-2]}$. Reference points out that system instability after a serious failure is due to the accelerated energy and the sharp drop in the delivery capacity. For mixed wind and thermal power plants, it is difficult to ensure the stability of system by only cutting thermal power generators when failure occurs, and it may lead to excessively high cost to cut off generators. In order to control the system frequency and voltage, ratio of cut thermal power cannot be too high, thus part of wind power must be cut as replacement to keep the system balanced. For a wind farm cluster, method to achieve the emergent active power abscission within a limited time is a problem to be solved.

By learning form the method of emergent active power control in thermal power plant, this paper proposes an algorithm of emergent active power control among wind power cluster. Considering the number of cut wind farms and the distribution deviation, the algorithm provides a way to achieve selective abscission of wind farms. Finally an example is used to verify the validity of proposed algorithm.

\section{METHOD OF EMERGENT ACTIVE POWER CONTROL}

\section{AMONG WIND POWER CLUSTER}

Emergent control needs to be rapid and effective. By analyzing the peculiarity of emergent active power control, this paper points out that, due to the response time level, only cutting wind farms can satisfy the rapid requirement of emergent power control.

\section{A. Emergent Active Power Control of Normal Thermal Power Plant}

For thermal power plant, abscission should be complete within limited time when emergent command is given.

The operating time is limited not more than $0.3-0.4 \mathrm{~s}$ to ensure the stability of system, or it may spent excessively high cost to control. For synchronous generators, turning off the valve and generator tripping are two main measures of emergent power control.

Since the time constant of turbine governor is greater than turbo-generator, valve control is only taken in thermal power plant to improve the system stability when failure occurs ${ }^{[3]}$. However, generator tripping can be used in both thermal and hydraulic plant. Mechanic output power can be decreased to a new ideal level through valve control ${ }^{[4]}$. For a certain plant, turning off valves can change the output power to 0 within $0.6-0.7 \mathrm{~s}^{[5]}$ and steam turbine can turn off all the valves in $0.3 \mathrm{~s}$ to complete abscission $^{[6]}$. In conclusion, generator tripping can be finished in $0.3 \mathrm{~s}$ for thermal plants and $50 \%-60 \%$ of power output can be decreased through rapid valve turning off in $0.3-.04 \mathrm{~s}$

There are 3 ways to distribute emergent power abscission for thermal plant: generator tripping, rapid turning off valves and the combination of both.

\section{B. Specialties of Emergent Active Power Control among Wind Power Cluster}

According to the requirement of thermal plant emergent power control and the specialty of wind farm cluster, the emergent power control is much different from the other controls of wind farm cluster, such as automatic threshold control, regulation control, slope control, deviation control and frequency control ${ }^{[7]}$.For example:

In time scale: Emergent control needs to be finished in hundreds micro seconds, when control unit is inaccessible, only generator tripping will satisfy the time limit, 
however, other power control is seconds-level or minutes-level ${ }^{[8]}$. This is similar to active power rescheduling and emergent abscission of thermal power plant.

The need of wind power prediction: The other controls mentioned above all need the prediction of wind power in the next period of time ${ }^{[9]}$, however since emergent control is completed in hundreds micro seconds, wind speed is considered to be constant, thus power prediction is not necessary for emergent active power control of among wind farms cluster.

The purpose of control: Emergent control aims to minimize the amount of cut wind farms and the control deviation, while the other control usually aims to maximize the output power.

\section{ALLOCATION ALGORITHM OF EMERGENT ACTIVE POWER ABSCISSION BASED ON COMBINATION OF CUT WIND FARMS}

Active power control of large scale wind farms is to ensure the safety and stability of power grid, so that wind energy resource can be made full use ${ }^{[10]}$.

According to the total abscission power which is $\Delta P$, when only generator tripping is accessible and abscission power should be no less than required, the target is to minimize the $D_{E}$, thus we get the active power allocation object function:

$$
\begin{gathered}
\min D_{E}=\min \left\{\sum_{i=1}^{n} \alpha_{i} P_{W i}-\Delta P\right\} \\
S . T \Delta P \leq \sum_{i=1}^{n} \alpha_{i} P_{W i} \alpha_{i} \in\{0,1\}, i=1,2 \ldots n
\end{gathered}
$$

In the equation, $P_{W i}$ is the current output power of number i wind farm, while character $\mathrm{n}$ represents the total number of wind farms which is related to the control, $\alpha_{i}$ decides whether a wind farm is cut, when $\alpha_{i}=1$, it means the number $i$ wind farm will be cut, while when $\alpha_{i}=0$, it means the number $\mathrm{i}$ farm will not be cut off, it will not participate the control.

The active power allocation algorithm based on cut wind farms aims to miniature the amount of cut wind farms $^{[11]}$.

If accumulated active power abscission is not taken into consideration, the imbalance of wind farms abscission may occur, which means some wind farms may get cut many times while the others never be cut once $^{[12]}$. To avoid this situation, this paper proposes an allocation algorithm based on the accumulated active power abscission ${ }^{[13]}$. In the equation below, $P_{i \sum Q T}$ means in a time cycle $\mathrm{T}$, the accumulate amount of active power abscission:

$$
P_{i \sum Q T}=\sum_{j=1}^{n} \Delta P_{W F j}
$$

In the equation, character $\mathrm{n}$ represents the number of times emergent control is taken in number $\mathrm{i}$ wind farm within a time cycle $\mathrm{T}, \Delta P_{W F j}$ is the allocated active power abscission in number $\mathrm{J}$ control process.

The equation below is the index to decide the order of abscission:
$g\left(P_{W i}, P_{i \sum Q T}\right)=\alpha\left(1+\frac{\Delta P_{m i}}{P_{\text {Base }}}\right)+\beta\left(10+\frac{P_{\text {Base }}}{P_{i \sum Q T}}\right)(10)$

In the equation, $\alpha$ and $\beta$ both are nonnegative integer, object to $\alpha+\beta=1$. If $\mathrm{P}_{\mathrm{i} \sum \mathrm{QT}}=0, \alpha=1$, or $\alpha=o$.

\section{EXAMPLE AND ANALYSIS}

An actual wind farm cluster is employed to verify the validity of proposed algorithm. This wind farm cluster is constituted by DFIG GE1.5WM $\mathrm{W}^{[14]}$, and is divided into 16 wind farms with $201 \mathrm{MW}$ installed capacity each and a single wind farm with $300 \mathrm{MW}$ installed capacity, the total capacity reaches to $3516 \mathrm{MW}^{[15]}$. The wiring diagram is shown in Fig .1, and the condition of each wind generator is shown in TABLE I.

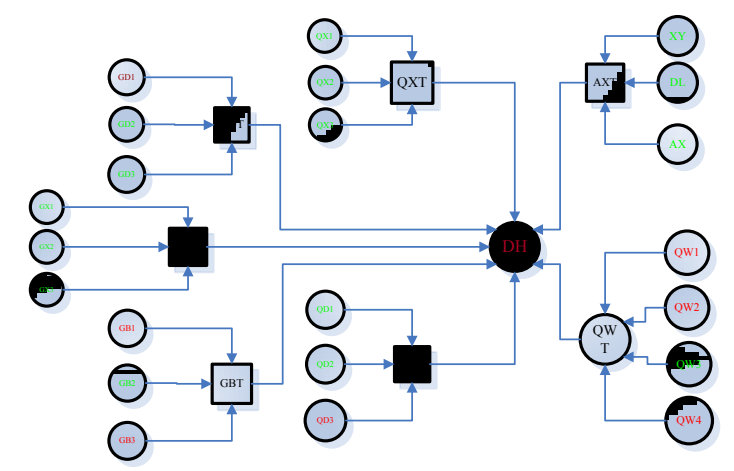

Figure 1. Wiring Diagram of Wind Farms in the Wind Farm Cluster

In the situation, a continuous 7 times emergent control is taken according to the allocation algorithm ${ }^{[16]}$, assuming that the initial accumulated active power abscission is $0^{[17]}$.

Example No.1:

A three phase short circuit fault occurs at a $750 \mathrm{KV}$ line out of the cluster, it is removed after $0.1 \mathrm{~s}^{[18]}$, the simulation result is shown at Fig .2. An extra more 250WM power needs to be cut off the wind farms cluster, the allocation result is shown in TABLE I.

Example No.2-No.7:

As the same method of example applied above, we get the result of other examples. The abscission required by dispatch center is $100 \mathrm{MW}, 150 \mathrm{MW}, 300 \mathrm{MW}, 400 \mathrm{MW}$, $500 \mathrm{MW}, 671 \mathrm{MW}$ for each example $\mathrm{e}^{[19]}$. Considering the accumulated cut power, we get the control order which is shown in TABLE II. In contrast, result of not considering accumulated cut power is shown in TABLE III.

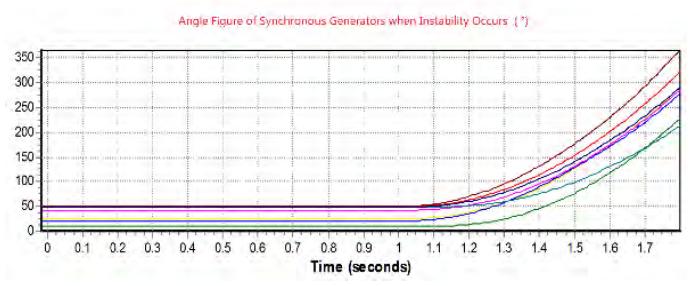

Figure 2. Power-Angle Curves of Synchronous Thermal Generators after Three Phase-Fault Applied at 750KV Line

It shows that without emergent control, the system angel will keep increasing, and finally system angle 
stability will be broken ${ }^{[20]}$. When emergent control is taken, the angle stability of system could maintain.

TABLE I. WIND FARMS' OPERATION SITUATION AND PARTICIPATING WIND FARMS OF EACH DISTRIBUTION METHOD OF CASE 1

\begin{tabular}{|c|c|c|c|}
\hline Wind farm & Serve signal & $\begin{array}{l}\text { active power } \\
(\mathrm{MW})\end{array}$ & $\begin{array}{l}\text { Wind farm } \\
\text { condition }\end{array}$ \\
\hline GD1 & $\mathrm{F}$ & - & - \\
\hline GD2 & $\mathrm{T}$ & 158.5 & 0 \\
\hline GD3 & $\mathrm{T}$ & 100.5 & 0 \\
\hline GX1 & $\mathrm{T}$ & 40.5 & 1 \\
\hline GX2 & $\mathrm{T}$ & 140.5 & 0 \\
\hline GX3 & $\mathrm{T}$ & 170 & 0 \\
\hline GB1 & F & - & - \\
\hline GB2 & $\mathrm{T}$ & 180 & 1 \\
\hline GB3 & $\mathrm{F}$ & - & - \\
\hline QX1 & $\mathrm{T}$ & 21 & 1 \\
\hline QX2 & $\mathrm{T}$ & 163 & 0 \\
\hline QX3 & $\mathrm{T}$ & 160.5 & 0 \\
\hline QD1 & $\mathrm{T}$ & 168 & 0 \\
\hline QD2 & $\mathrm{T}$ & 173 & 0 \\
\hline QD3 & F & - & - \\
\hline QW1 & $\mathrm{F}$ & - & - \\
\hline QW2 & F & - & - \\
\hline QW3 & $\mathrm{T}$ & 176 & 0 \\
\hline QW4 & $\mathrm{F}$ & - & - \\
\hline Cluster & $\mathrm{T}$ & $1651.5 \mathrm{MW}$ & - \\
\hline
\end{tabular}

note: "F" means not in serve,"T" means in serve,"1" means cut off,"0" means not cut off, “_” means nonsense .

TABLE II. WIND FARMS' CONTROL SEQUENCE OF EACH CASE OF METHOD 4

\begin{tabular}{lllllll}
\hline \multirow{2}{*}{ Wind farm } & \multicolumn{5}{c}{ Example number } \\
\cline { 2 - 6 } & C2 & C3 & C4 & C5 & C6 & C7 \\
\hline GD2 & 6 & 5 & 4 & 2 & 9 & 7 \\
GD3 & 8 & 7 & 6 & 4 & 1 & 3 \\
GX1 & 9 & 8 & 7 & 5 & 2 & 2 \\
GX2 & 7 & 6 & 5 & 3 & 5 & 11 \\
GX3 & 2 & 1 & 11 & 10 & 8 & 6 \\
GB2 & 12 & 12 & 12 & 12 & 12 & 10 \\
QX1 & 10 & 9 & 8 & 6 & 3 & 1 \\
QX2 & 4 & 3 & 2 & 9 & 7 & 5 \\
QX3 & 5 & 4 & 3 & 1 & 10 & 8 \\
QD1 & 3 & 2 & 1 & 11 & 11 & 9 \\
QD2 & 1 & 11 & 10 & 8 & 6 & 4 \\
QW3 & 11 & 10 & 9 & 7 & 4 & 12 \\
\hline & & & & & &
\end{tabular}

Comparing the results, we will find that control order is decided by accumulated cut power, and changes frequently. Without the accumulated cut power algorithm, the order and times of cut wind farm is unbalanced and unfair, when accumulated abscission of wind farms is considered, the allocation solution becomes more reasonable.

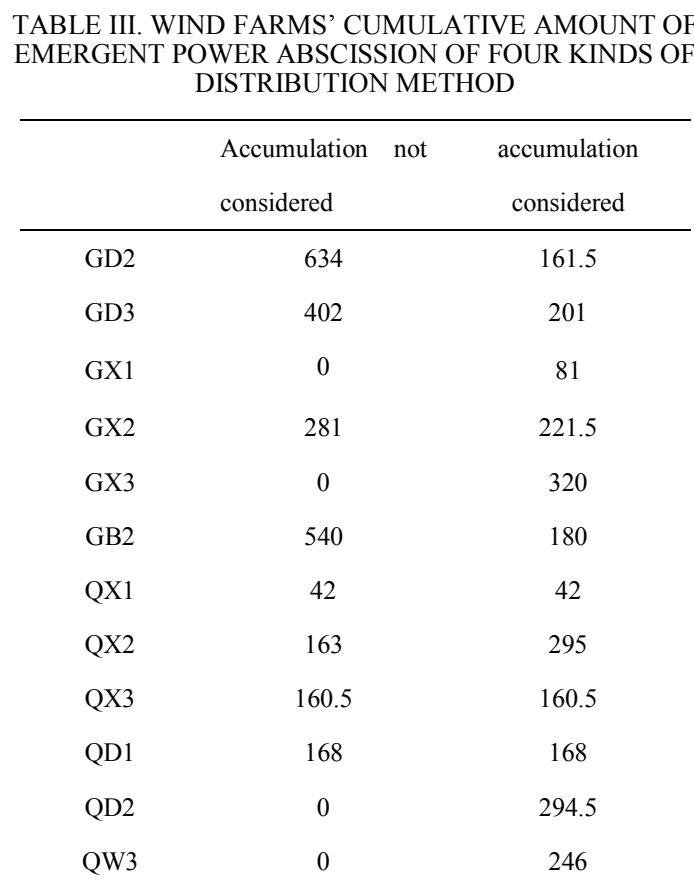

According the TABLE III, we find that the allocation algorithm based on combination of cut wind farms is simple and fair while it may lead to over cutting.

\section{CONCLUSION}

As the proportion of wind power rapidly increases, abscission of wind farms must be considered in case of an emergency. This paper proposes an allocation algorithm based on accumulated cut wind farms to solve the problem. Then an actual wind farm cluster is used as an example to verify the validity of the proposed algorithm. Result shows that the allocation algorithm improves the balance of cutting off wind farms cluster, in the same time the allocation algorithm has a wide application scope.

\section{REFERENCES}

[1] DING Jian, QIU Yuefeng, SUN Huadong, et al. Consideration of Wind Generator Tripping Under Large-scale Wind Power Integration [J]. Proceeding of the CSEE, 2011, 31(19): 25-36.

[2] CHEN Shuyong, CHEN Huiyuan, TANG Xiaojun, et al. Generator Tripping Control To Uphold Transient Stability Of Power Grid Outwards[J]. Power System Technology, 2013, 37(2): 514-519.

[3] Technical rule for connecting wind farm to power network[S]. China: State Grid, 2006.

[4] LIN Li, WANG Shiqian, TAN Juan. Wind Power Control Considering System Frequency Regulation[J]. electric power , 2011, (09): 22-25.

[5] Rodriguez-Amanedo JL, Arnalte S, Burgos JC. Automatic generation control of wind farm with variable speed wind turbines. IEEE Trans Energy Conver 2002;17(2):279-84. 
[6] LIU Junqiao, Rosyadi M, Takahashi R, Tamura J, Fukushima T, Sakahara A, Shinya K, Yosioka K. "A new pitch control system of wind turbine to damp power system frequency fluctuations," Renewable Energy Research and Applications (ICRERA), 2012 International Conference on , vol., no., pp.1,5, 11-14 Nov. 2012.

[7] QIAO Ying, LU Zongxiang. Wind Farms Active Power Control Considering Constraints of Power Grids[J]. Automation of Electric Power System , 2009, (22): 88-93.

[8] LIN Li, XIE Yongjun, ZHU chenchen, et al. Priority List-Based Output-Restricted Active Power Control Strategy for Wind Farms[J]. Power System Technology, 2013, (4): 960-966.

[9] WANG Shiqian. Research On Active Power Control Strategy of Wind Farm with DFIGs[D]. Beijing : North China Electric Power University, 2012.

[10] XING Zhou, CHEN Yonghua, CHEN Zhenhuan, et al. A Control Strategy of Active Power Intelligent Control System for Large Cluster of Wind Farms Part One Coordinating Control for Wind Farms[J]. automation of electric power system , 2011, (20): 20-23.

[11] XU Rui, GAO ZongHe, TENG Xianliang. "Real-time dispatching and coordinated control of large capacity wind power integration," Advanced Power System Automation and Protection (APAP), 2011 International Conference on , vol.1, no., pp.49,53, 16-20 Oct. 2011.

[12] WANG Jun. Research on Real Time Emergency Control of Power System[D]. Zhejiang:Zhejiang University, 2005.
[13] TANG Yong, BU Guangquan, HOU Junxian. Transient Stability Program User Manual of PSD-BPA[Z]. Beijing: China Electric Power Research Institute,2005.

[14] MENG Dingzhong. Fast Valving Test of Steam Turbine[J]. Power system Technology, 1999, (12): 11-15.

[15] ZHANG You. Research and Test on Improving Power System Stability by Fast Valving [J]. Power system Technology, 1996, (12): $11-15$.

[16] FANG Guocheng, ZHAO Yidan. Time Adjusting on Steam-valve System for $1000 \mathrm{MW}$ Ultra Supercritical Generating Units[J]. Northeast Electric Power Technology, 2010, (09): 11-14.

[17] Anca D. Hansen, PoulSørensen, Florin Iov, FredeBlaabjerg, Centralised power control of wind farm with doubly fed induction generators, Renewable Energy, Volume 31, Issue 7, June 2006, Pages 935-951.

[18] DING Ming, LI Shenghu, WU Hongbing, et al. Analysis of Power System Operation State Based on Adequacy and Security [J]. proceeding of the CSEE, 2004, (4): 47-53.

[19] LIU Wei, HUANG Yuehui, LIU Chun, et al. Study on Algorithm of Power Curtailment among Wind Farms[J]. electrical power , 2011, (8): 53-56.

[20] XIAO Jun, CUI Yangyan, WANG Jianmin. A Hierarchical Performance Assessment Method on the Distribution Network Planning[J]. Automation Of Electric Power System , 2008, (15): $36-40$. 